\title{
Olgu bildirimi \\ Horizontal kök kırıklı bir dişin dekoronasyon ile tedavisi: olgu bildirimi
}

\author{
Selen Esin Yoldaş, ${ }^{1 *}$ Haluk Bodur, ${ }^{1}$ \\ Sercan Küçükkurt ${ }^{2}$ \\ ${ }^{1}$ Pedodonti Anabilim Dalı, ${ }^{2}$ Ağız ve Çene Cerrahisi Anabilim \\ Dalı, Gazi Üniversitesi Diş Hekimliği Fakültesi, Ankara, \\ Türkiye
}

\section{ÖZET}

TANITIM: Travma sebebiyle daimi anterior dişlerin erken kaybı genç hastalarda estetik ve fonksiyonel pek çok soruna yol açmaktadır. Diş eksikliklerinin konvansiyonel yöntemlerle tedavisi, ilerleyen dönemde gerçekleştirilebilecek daimi estetik tedavileri zorlaştırmaktadır. Bu durumun önüne geçmek için alternatif tedavi yöntemleri uygulanmaya başlanmıştır. Bu yöntemlerden biri ankiloze dişler için uygulanan, diş kronunun çıkarılarak kökün alveoler soket içinde bırakılması aşamalarını içeren dekoronasyon işlemidir.

OLGu BiLdiRimi: Travma hikayesiyle Gazi Üniversitesi Diş Hekimliği Fakültesi Çocuk Diş Hekimliği Anabilim Dalına başvuran 12 yaşındaki erkek hastanın 11 numaralı dişinde komplike kron kırığı, 21 numaralı dişinde kök kırığı tespit edildi. Kron kırığı bulunan 11 numaralı diş, kanal tedavisini takiben fiber post ve strip kron uygulamalarıyla restore edildi. Çekim endikasyonu bulunan horizontal kök kırıklı 21 numaralı dişe ise dekoronasyon uygulanarak, erken diş çekimine bağlı oluşabilecek alveol kemik kaybının önlenmesi amaçlandı. Eksik diş boşluğu hareketli protez ile restore edildi. Hasta altışar aylık aralıklarla kontrol randevularına çağırıldı, 18 ay boyunca takip edildi. Takip süresi boyunca hastada, ilgili bölgede alveol kemik seviyesinde azalma oluşmadığı, herhangi bir enfeksiyon bulgusu gelişmediği gözlendi. Dekorone 21 numaralı dişte rezorpsiyon devam etmektedir. 11 numaralı dişin de asemptomatik olduğu görüldü. Hasta halen kontrol altındadır.

Sonuç: Dekoronasyon, çekimi planlanan ankiloze dişlerde alveol kemik kaybının önlenmesi açısından güvenle kullanılabilecek bir tedavi seçeneğidir. Bu olguda, uygun endikasyonda ankiloze olmayan dişlerde de bu tekniğin kullanılabileceği görülmüştür.

Makale gönderiliş tarihi: 26 Kasım 2014; Yayına kabul tarihi: 4 Ocak 2015 *iletişim: Selen Esin Yoldaş, Gazi Üniversitesi Diş Hekimliği Fakültesi, Pedodonti Anabilim Dalı, 8. Cadde, 82. Sokak, No: 4, 06510, Emek, Ankara, Türkiye

E-posta: selenesinyoldas@gmail.com

\begin{abstract}
Anahtar Kelimeler: Dekoronasyon; diş kırıkları; travma
\end{abstract}
Kaynak Göstermek İçin: Yoldaş SE, Bodur H, Küçükkurt S. Horizontal kök kırıkı bir dişin dekoronasyon ile tedavisi: olgu bildirimi. Acta Odontol Turc 2016;33(2):91-4

ЕрітӧR: Neşe Akal, Gazi Üniversitesi, Ankara, Türkiye

YAYıN HAKKI: @ 2016 Yoldaş ve ark. Bu eserin yayın hakkı Creative Commons Attribution License ile ruhsatlandırılmıştır. Sınırsız kullanım, dağıtım ve her türlü ortamda çoğaltım, yazarlar ve kaynağın belirtilmesi kaydıyla serbesttir.

[Abstract in English is at the end of the manuscript]

\section{Giriş}

Kök kırıkları sement, dentin ve pulpayı içeren, yalnız diş kökünü ya da kron ve kökü birlikte etkileyebilen komplike diş yaralanmalarıdır. En sık olarak maksiller kesici dişler etkilenmekte ve görülme sıklığı \%2-7 arasında değişiklik göstermektedir. En sık etkilenen yaş grupları süt dentisyonda 3-4 yaş, daimi dentisyonda ise 11-20 yaşlar olarak belirtilmiştir. Özellikle kemik ve yumuşak dokuların yaralanmaları eşlik ettiğinde, kök kırıklarının tedavileri klinisyenler için oldukça zorlayıcı olabilmektedir. Kök kırıklarında prognoz, kırık hattının yeri ve fragmanlar arası iyileşmenin ne şekilde gerçekleştiğine bağlıdır. ${ }^{1-3}$

Dekoronasyon işlemi 1984 yılında, ankiloze dişlerin çekimine alternatif olarak ortaya atılmış bir tekniktir. Ankiloze dişlerin çekimi oldukça fazla miktarda kemiğin kaybedilmesine sebep olmaktadır. Bu durum da hastaya ilerleyen dönemde estetik restorasyonlar yapılmasını güçleştirmektedir. Dekoronasyon işlemi ankiloze dişler için mukoperiosteal flep kaldırımasının ardından diş kronunun çıkarılması, kalan diş kökünün içinde, kök ucu travmatize edilerek kanama oluşturulması ve diş kökünün üzeri tamamen mukoza ile kapanacak şekilde flebin kapatılması aşamalarını içermektedir. Dekoronasyon işlemi ile yapılan tedavilerde uzun dönemde oldukça başarılı sonuçlar elde edilmiştir. ${ }^{4,5}$

Filippi ve arkadaşlarının ${ }^{6} 2001$ yılında yayımlanan vaka raporlarında, dekoronasyon uygulanan 16 yaşındaki hastanın 9 ay boyunca takip edildiği, dekoro- 
nasyon uygulanan bölgede kemik apozisyonunun gözlendiği belirtilmiştir. Cohenca ve Stabholz, 15 yaşında erkek hastanın ankiloze halde bulunan santral dişine dekoronasyon uygulamış, 2.5 yıl sonra hastanın implant uygulaması için uygun olduğunu belirtmişlerdir. ${ }^{7}$ Diaz ve arkadaşlarının ${ }^{8}$ yayımlanan vaka raporunda 9.5 yaşında erkek hastanın ankiloz teşhisi konmuş santral dişine dekoronasyon uygulanmış, dekoronasyondan 44 ay sonra radyografta az bir miktarda kök parçasının görünür kaldığı, kemik apozisyonunun izlenmekte olduğu belirtilmiştir.

Bu olguda, kök kırığı bulunan ve çekim endikasyonu konulmuş bir santral diş için, çekim yerine alveoler kemik kaybının önlenmesi ve dolayısıyla uzun vadede estetiğin korunması amacıyla dekoronasyon prosedürü aşamaları uygulanmıştır. Hasta 18 ay boyunca takip edilmiştir.

\section{OLgu BiLdiRimi}

12 yaşında bir erkek hasta Gazi Üniversitesi Diş Hekimliği Fakültesi Çocuk Diş Hekimliği Anabilim dalına travma hikayesi ile başvurdu. Alınan anamneze göre, hastanın 1 yıl önce düşme sonucu ön iki dişinde kırık meydana geldiği, tedavinin travmadan bir gün sonra başka bir sağlık kurumunda başlatıldığı, ancak hastanın tedaviye devam etmediği öğrenildi. Yapılan klinik muayenede 11 numaralı dişin servikal üçlüsünde horizontal kron kırığı, 21 numaralı dişin orta üçlüsünde ise oblik kron kırığı tespit edildi. Ayrıca 11 ve 21 numaralı dişlere daha önceden endodontik açılmış giriş kavitelerinin açık halde bulunduğu görüldü. Dişlere kanal tedavisi başlandığı, ancak geçici restorasyonların düşmüş olduğu anlaşıldı. Diş kronları üzerinde daha önce yapılmış splintten kaldığı anlaşılan kompozit rezin artıklarına rastlandı (Resim 1A).

Radyografik muayenede 11 numaralı dişin periapikalinde radyolusent lezyon ve 21 numaralı diş kökünün apikal üçlüsünde horizontal kök kırığı tespit edildi (Resim 1B). Tedavi planlamasında, 11 ve 21 numaralı dişlerin kanal tedavilerinin tamamlanması ve her iki dişin kanal içi post ve kompozit rezin uygulamalarıyla restore edilmesi kararlaştırıldı.

Hasta ikinci randevu için kliniğe geldiğinde 21 numaralı diş kronunun da servikal üçlüden kırıldığı görüldü (Resim 2). Buna göre yeni bir tedavi planı oluşturuldu.

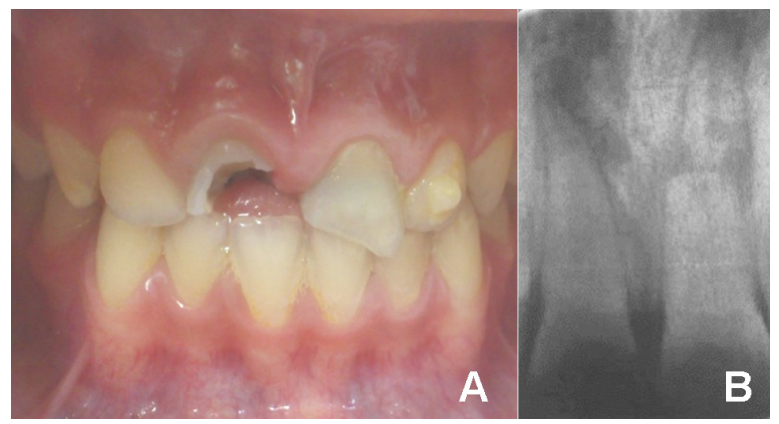

Resim 1. A: Başlangıç ağız içi görünümü, B: Başlangıç radyografisi
Kanal tedavisini takiben, 11 numaralı diş, kanal içi post ve kompozit uygulamalarıyla restore edildi. Diğer dişin (diş no. 21) apikalindeki kök parçası çıkarılarak kalan kök fragmanı dekorone edildi (Resim 3A). Eksik diş boşluğu hareketli protez ile restore edildi. (Resim 4) Hasta 6, 12 ve 18. aylarda kontrol randevularına çağırıldı. Hastanın herhangi bir şikayetinin bulunmadığı görüldü. Kontrol randevularında alınan radyografilerde 11 numaralı dişin periapikalinde bulunan radyolusent lezyonun tamamen iyileştiği gözlendi. Alveol kemik içerisinde bırakılan kök parçasının rezorbe olmaya devam ettiği görüldü. İzlenen 18 ay içerisinde radyografik olarak alveol kemik seviyesinde azalma oluşmadığı görüldü (Resim 3B-D).

\section{TARTIŞMA}

Kaybedilmiş ön diş eksikliklerinin rehabilitasyonu hastalar için, diş ile birlikte kaybedilen fonksiyon ve özellikle estetiğin yeniden sağlanması açısından oldukça önemlidir. Anterior tek diş eksikliklerinin tedavisi hareketli parsiyel protezler, Maryland köprüler, adeziv köprüler, sabit parsiyel protezler ya da dental implantlar kullanılarak gerçekleştirilebilir. Hangi tedavi yönteminin seçileceği simetrik dişin renk ve şekline, diş boşluğunun boyutuna, hastanın kapanışına, parafonksiyonel alışkanlıkların varlığına, alveol kemik seviyesine, hastanın estetik beklentilerine ve hastanın yaşına bağlıdır. ${ }^{9-11}$

Belirtilen tedavi alternatiflerinin tamamının avantaj ve dezavantajları bulunmakla birlikte, günümüzde literatürde en avantajı olarak belirtilen yöntem dental implantların kullanımıdır. Ancak dental implantların büyüme ve gelişimi devam eden çocuk hastalarda kullanımının; erken yaşta uygulanacak implantların çenelerin büyümesine bağlı olarak yer değiştirebileceği ve uygulandığı bölgedeki büyümeyi olumsuz etkileyebileceği belirtilmiştir. Bu sebeplerle dental implantların ciddi hipodonti ya da anadontisi bulunan ektodermal displazili hastalar dışında, büyüme gelişimi tamamlanmayan hastalarda uygulanması tartışmalıdır. ${ }^{12}$

İmplant uygulaması sonrası başarılı estetik sonuçlar elde edilmesi pek çok faktöre bağlıdır. Diş çekiminden sonra alveol kemiğinde meydana gelen

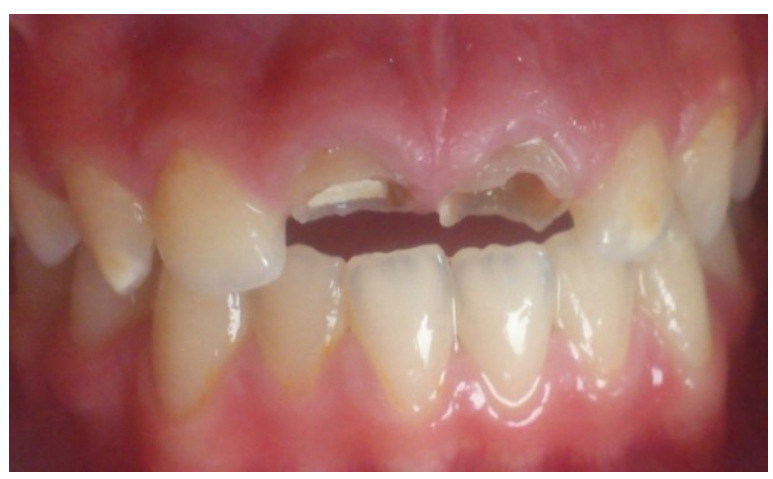

Resim 2. 11 ve 21 numaralı dişlerde tekrarlayan travma üzerine meydana gelen kron kırıkları 


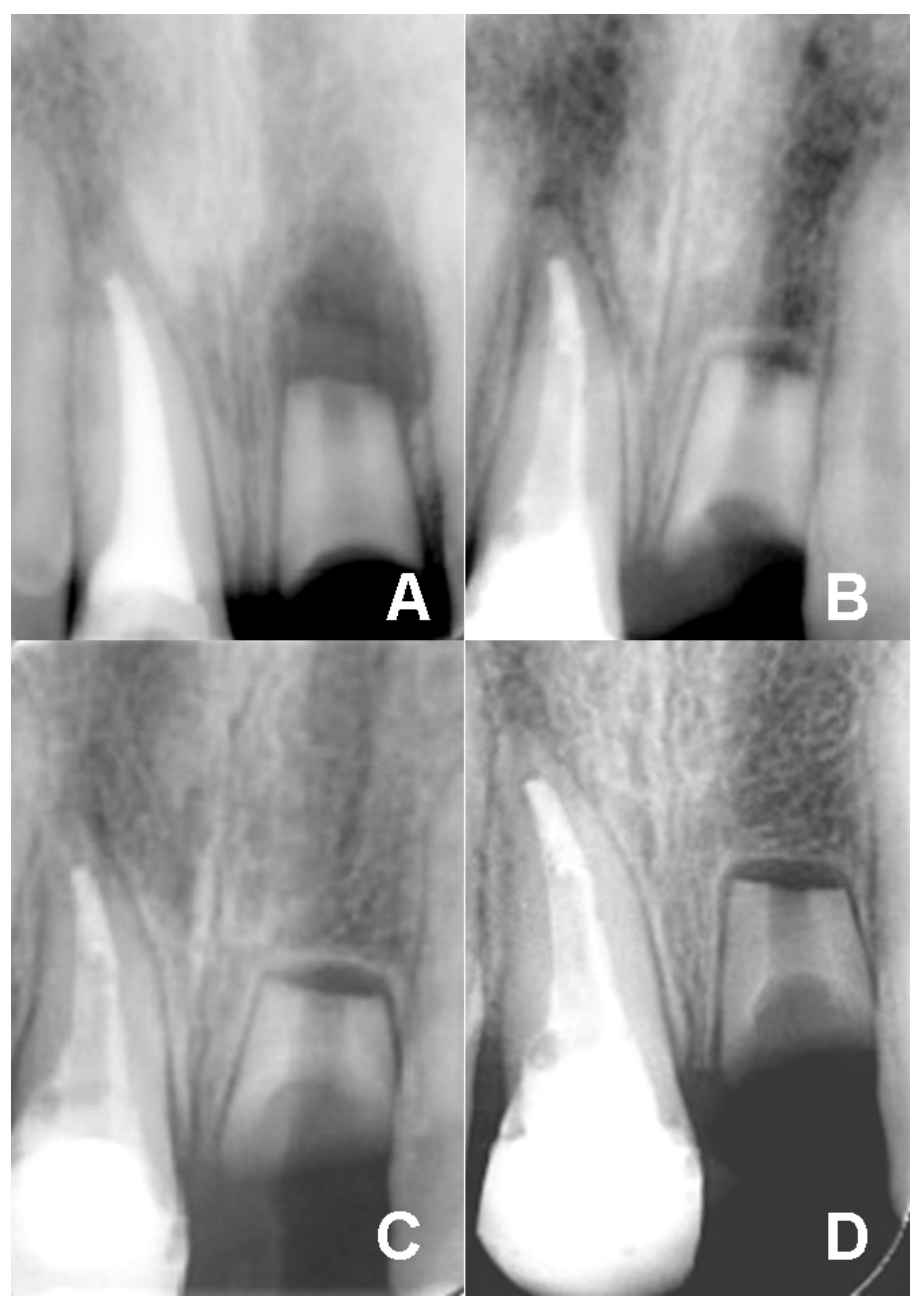

Resim 3. A: Apikal kırık parçanın çıkartımasııı içeren operasyon sonrası radyografisi, B: 6. ay kontrol radyografisi, C: 12. ay kontrol radyografisi, D: 18. ay kontrol radyografisi

rezorpsiyon, implantın yerleştirilmesiyle ve estetikle ilgili pek çok soruna yol açabilir. Çocuk hastalarda özellikle travmaya bağlı olarak anterior dişlerin erken yaşta kaybedilmesi ve implant uygulaması için büyüme gelişmenin tamamlanmasının beklenmesi dolayısıyla, uygun zaman geldiğinde estetik implant uygulamaları yapabilmek klinisyenler için güçleşmektedir. ${ }^{13}$

Dekoronasyon, ankiloze dişlerin çekimi ile oluşabilecek ciddi kemik kaybının önlenmesi amacıyla diş kronunun servikal marjinin hemen altına kadar olan kısmının çıkarılması ve kalan kök parçasının alveol soket içerisinde bırakılması aşamalarını içeren bir tekniktir. Rezorbe olmakta olan diş kökünün çevresinde, interdental ve dentoperiosteal fibrillerdeki aktiviteye bağlı olarak yeni periosteum oluştuğu ve dolayısıyla kemik apozisyonu gözlendiği belirtilmektedir. ${ }^{14,15}$ Benzer şekilde, bu olguda da soket içerisinde bırakılan kök parçası çevresindeki kemik miktarında artış gözlenmiştir.

Diş çekimi komplikasyonu olarak kök kırığı meydana geldiğinde kökün alveoler soket içerisinde bırakılması ancak kök parçasının 4-5 mm'den küçük olması, yüzeyel konumda olmaması ve enfekte olmaması koşullarında önerilmektedir. ${ }^{16}$ Dekoronasyon işleminde ise kök içi kanamanın periapikal dokulardan sağlanması dolayısıyla, kökün enfekte olmadığı belirtilmiştir. ${ }^{14} \mathrm{Bu}$ olguda da soket içerisinde bırakılan kök fragmanı içinde periapikal dokular irrite edilerek kanama sağlanmış, takip sürecinde herhangi bir enfeksiyon bulgusu gelişmemiştir.

Bu olguda, çekim endikasyonu bulunan bir dişin kök parçası, dekoronasyon prosedürü uygulanarak soket içinde bırakılmıştır. Bu işlemle, erken yaşta yapılan diş çekimi dolayısıyla oluşabilecek kemik kaybının önüne geçilerek, hastanın büyüme gelişimi tamamlandığında estetik bir implant uygulaması yapılabilmesine olanak sağlanması amaçlanmıştır.

Dekoronasyon işlemi, ilk ortaya atıldığı günden bugüne özellikle avülsiyon sonrası ankiloz meydana gelen dişlerde uygulanmıştır. ${ }^{6-8} \mathrm{Bu}$ olguda ise, ankiloze olmayan çekim endikasyonlu bir dişe dekoronasyon uygulanmıştır. Literatürde ankiloze olmayan dişler için dekoronasyon uygulaması örneğine rastlanmamıştır. Dekoronasyon işlemi sırasında, soket içerisinde bırakılacak kök içinde, periapikal dokular irrite edilerek kanama oluşturulması dolayısıyla, bu olguda soket 
içerisinde bırakılan kökte enfeksiyon oluşmamıştır. 18 aylık takip süresi boyunca hastada herhangi bir semptom gelişmediği gözlenmiştir. Diş kökü rezorpsiyonunun tamamlanmasına kadar geçen süre, diş çekiminden sonra gelişecek alveoler kemik kaybı oluşumunun başlangıcını geciktirmesi ve dolayısıyla toplamda meydana gelebilecek alveoler kemik kaybının azaltılabilecek olması açısından vakit kazanımı olarak değerlendirilmiştir. Ankiloze olmayan dişlerde bu yöntemin başarı ile uygulanabilmesi için uygun yaş ve endikasyonda hasta seçimi yapılması oldukça önemlidir.

\section{Sonuç}

Takip süresi boyunca hastada, ilgili bölgede alveol kemik seviyesinde azalma oluşmadığı, herhangi bir enfeksiyon bulgusu gelişmediği gözlenmiştir. 21 numaralı dişte rezorpsiyon devam etmektedir. 11 numaralı dişin de asemptomatik olduğu görülmüştür. Hasta halen kontrol altındadır. Dekoronasyon çekimi düşünülen ankiloze dişlerde alveol kemik kaybının önlenmesi açısından güvenle kullanılabilecek bir tedavi seçeneğidir. Bu olguda, uygun endikasyonda ankiloze olmayan dişlerde de bu tekniğin kullanılabileceği görülmüştür.

Çıkar çatışması: Yazarlar bu çalışmayla ilgili herhangi bir çıkar çatışmalarının bulunmadığını bildirmişlerdir.

\section{KAYNAKLAR}

1. Diangelis AJ, Andreasen JO, Ebeleseder KA, Kenny DJ, Trope M, Sigurdsson A et al. International Association of Dental Traumatology guidelines for the management of traumatic dental injuries: 1. Fractures and luxations of permanent teeth. Dent Traumatol 2012;28:2-12.

2. Yıldııım T, Gençoğlu N. Use of mineral trioxide aggregate in the treatment of horizontal root fractures with a 5 year follow-up: report of a case. J Endod 2009;35:292-5.

3. Majorana A, Pasini S, Bardellini E, Keller E. Clinical and epidemiological study of traumatic root fractures. Dent Traumatol 2002;18:77-80.

4. Cohenca N, Stabholz A. Decoronation - a conservative method to treat ankylosed teeth for preservation of alveolar ridge prior to permanent prosthetic reconstruction: literature review and case presentation. Dent Traumatol 2007;23:87-94

5. Sapir S, Kalter A, Sapir MR. Decoronation of an ankylosed permanent incisor: alveolar ridge preservation and rehabilitation by an implant supported porcelain crown. Dent Traumatol 2009;25:346-9.

6. Filippi A, Pohl Y, von Arx T. Decoronation of an ankylosed tooth for preservation of alveolar bone prior to impant placement. Dent Traumatol 2001;17:93-5.

7. Cohenca N, Stabholz A. Decoronation-a conservative method to treat ankylosed tooth for preservation of alveolar ridge prior to permanen prosthetic reconstruction: literature review and case presentation. Dent Traumatol 2007;23:81-94

8. Diaz JA, Sandoval HP, Pineda PI, Junod PA. Conservative treatment of an ankylosed tooth after delayed replantation: a case report. Dent Traumatol 2007;23:313-7.
9. Chafaie A, Portier R. Anterior fiber reinforced composite resin bridge: a case report. Pediatr Dent 2004;26:530-4.

10. Kim H, Song MJ, Shin SJ, Lee Y, Park JW. Esthetic rehabilitation of single anterior edentulous space using fiber reinforced composite. Restor Dent Endod 2014;39:220-5.

11. Al-Quran FA, Al-Ghalayini RF, Al-Zu'bi BN. Single tooth replacement: factors affecting different prosthetic treatment modalities. BMC Oral Health 2011;21:11-34.

12. Mishra SK, Chowdhary N, Chowdhary R. Dental implants in growing children. J Indian Soc Pedod Prev Dent 2013;31:3-9.

13. Sammartino G, Marenzi G, di Lauro AE, Paolanntoni G. Aesthetics in oral implantology: biological, clinical, surgical and prosthetic aspects. Implant Dent 2007;16:54-65.

14. Malmgren B. Ridge preservation/decoronation. Pediatr Dent 2013;35:164-9.

15. Malmgren $B$, Malmgren $O$, Andreasen JO. Alveolar bone devolopment after decoronation of ankylosed teeth. $J$ Endod 2006;14:35-40.

16. Datarkar NA. Exodontia Practice, 1st edn. New Delhi: Jaypee Brothers Publishing; 2007.

\section{Treatment of a horizontal root-fractured tooth with decoronation procedure: case report}

\section{Abstract}

INTRODUCTION: Early loss of permanent anterior teeth due to trauma can cause esthetic and functional problems for young patients. In such cases, replacement of the missing tooth with traditional approaches is possible; however such approaches will reduce the chance of the patient to receive an esthetic and consistent treatment in the future.

CASE RePort: A 12-year-old male patient referred to our clinic with a history of trauma. Complicated crown fracture in tooth no.11 and horizontal root fracture in tooth no. 21 was detected. Following root canal treatment, tooth no. 11 was restored with a fiber post and a strip crown. To avoid alveolar bone loss due to early tooth extraction, decoronation procedure, an alternative approach, was applied to tooth no. 21. This procedure consisted of leaving the root fragment inside the alveolar socket following the removal of the crown. For the rehabilitation of the missing crown, a partial removable prosthesis was implemented. The patient was recalled in 6., 12. and 18. months. Within the follow-up period, no reduction in the alveolar bone level was seen. No sign of infection was evident. The remaining root fragment kept on resorbing. Tooth no. 11 remained symptom-free as well. The patient is still being followed.

Conclusion: Decoronation is essentially a treatment choice for preventing alveolar bone loss in ankylosed teeth considered for extraction. In this case report, decoronation was shown to be a suitable alternative also for a fractured, non-ankylosed tooth.

KEYWORDS: Decoronation; tooth fractures; trauma 